\title{
LA DEFINICIÓN CONSTITUCIONAL DEL DERECHO A LA TUTELA JUDICIAL EFECTIVA
}

MANUEL CARRASCO DURÁN 


\section{SUMARIO}

Introducción. - 1. El derecho a la tutela judicial efectiva como concepto difícil de comunicar fuera del ámbito académico. - 2. El derecho a la tutela judicial efectiva es un derecho fundamental, con todo lo que esto comporta. - 3. El juicio de razonabilidad: vertientes y tests. - 4. Conclusiones y crítica. - Bibliografía. 


\title{
LA DEFINICIÓN CONSTITUCIONAL DEL DERECHO A LA TUTELA JUDICIAL EFECTIVA
}

\author{
MANUEL CARRASCO DURÁN ${ }^{1}$ \\ Profesor Titular de Derecho Constitucional de la Universidad de Sevilla \\ Letrado del Parlamento de Andalucía
}

\section{INTRODUCCIÓN}

El derecho a la tutela judicial efectiva ha generado la mayor parte de los asuntos que ha tenido que resolver el Tribunal Constitucional a través del recurso de amparo ${ }^{2}$. Ha dado lugar también a un buen número de recursos y cuestiones de inconstitucionalidad ${ }^{3}$. Es, asimismo, como consecuencia, el derecho sobre el que el Tribunal Constitucional ha elaborado una doctrina más extensa, a partir de la resolución de una infinidad de casos. Y, sin embargo, es poco lo que se ha escrito sobre el derecho a la tutela judicial efectiva en el ámbito del Derecho Constitucional ${ }^{4}$.

1 Datos de contacto: Manuel Carrasco Durán. Parlamento de Andalucía. Servicios Jurídicos. c/. San Juan de Ribera, s/n / 41009 Sevilla. Correo electrónico: m.carrasco@parlamento-and.es / carrasco@us.es

2 El hecho es conocido. Valga como botón de muestra que, según la Memoria del Tribunal Constitucional de 2018, el derecho a la tutela judicial sin indefensión del artículo 24.1 de la Constitución fue alegado en 5.309 recursos de amparo, sobre un total de 6.918 presentados en dicho año. Vid. Tribunal Constitucional. Memoria. 2018, pág. 226.

3 En el presente trabajo, estudiamos la interpretación del derecho a la tutela judicial efectiva sobre la base de las sentencias dictadas en recursos de amparo. El derecho a la tutela judicial efectiva en el ámbito de los procesos de declaración de inconstitucionalidad frente a normas con fuerza de ley ofrece una problemática diferente. Mientras en los recursos de amparo se precisa la interpretación de los artículos de la Constitución con el fin de ofrecer una solución a un asunto, para lo cual se emplean criterios hermenéuticos tales como los basados en la ponderación de derechos y en la proporcionalidad, en los procesos de declaración de inconstitucionalidad con fuerza de ley se trata de ofrecer una interpretación de límites, que delimite las fronteras de desarrollo de los artículos de la Constitución, dentro de las cuales el legislador, normalmente, ha de tener un margen amplio de opciones de concreción.

${ }^{4}$ Como trabajos monográficos, destacamos FIGUERUELO BURRIEZA, A. (1990). El derecho a la tutela judicial efectiva, Madrid, Tecnos, BORRAJO INIESTA, I., DÍEZ-PICAZO GIMÉNEZ, I. y FERNÁNDEZ FARRERES, G. (1995). El derecho a la tutela judicial y el recurso de amparo. Una reflexión sobre la jurisprudencia constitucional, Madrid, Civitas, RUIZ-RICO RUIZ, G. y CARAZO LIÉBANA, M. J. 
Influyen en lo anterior varios factores, como la percepción extendida sobre la naturaleza predominantemente procesal de este derecho, la «mala fama» que acompaña a este derecho como causante del exceso de recursos de amparo que tradicionalmente ha sufrido el Tribunal Constitucional y la propia abundancia de la jurisprudencia sobre este derecho, que, sin duda, dificulta su estudio. Sin embargo, no puede olvidarse que se trata de un derecho fundamental dotado de la máxima protección por la Constitución y que concita una alta demanda en el ámbito jurídico de trabajos que lo desarrollen y precisen.

El origen de este trabajo se encuentra en la intuición de que, tras el enorme número de recursos de amparo basados en el derecho a la tutela judicial que es inadmitido por el Tribunal Constitucional ${ }^{5}$, suele haber una defectuosa comprensión de su definición por parte de los profesionales del Derecho. Se trata de un derecho que ha venido siendo entendido como de naturaleza procesal, cuando debe ser definido conforme a su naturaleza constitucional. El presente trabajo, precisamente, trata de arrojar luz sobre la definición constitucional del derecho a la tutela judicial efectiva.

\section{EL DERECHO A LA TUTELA JUDICIAL EFECTIVA COMO CONCEPTO DIFÍCIL DE COMUNICAR FUERA DEL ÁMBITO ACADÉMICO}

El derecho a la tutela judicial es uno de los que más difícil resulta de hacer entender por operadores jurídicos que no pertenecen al reducido ámbito académico. Ello se debe a que el concepto de tutela que maneja el Tribunal Constitucional es muy diferente del que habitualmente se utiliza en las relaciones sociales.

En una de las acepciones que recoge el Diccionario de la Real Academia Española de la Lengua se define a la tutela como defensa de una persona respecto de otra. Esto entronca con el concepto que habitualmente se maneja de la expresión tutela judicial,

(2013). El derecho a la tutela judicial efectiva. Análisis jurisprudencial, Valencia, Tirant lo Blanch, MILIONE, C. (2015). El derecho a la tutela judicial efectiva en la jurisprudencia del Tribunal Europea de Derechos Humanos, Valencia, Tirant lo Blanch, y CARRASCO DURÁN, M. (2018). El derecho a la tutela judicial efectiva sin indefensión, Cizur Menor, Aranzadi. Para el examen de la manera en que ha afectado a la interpretación del derecho a la tutela judicial la aplicación de la especial trascendencia constitucional como requisito para la admisión de los recursos de amparo, vid. NARANJO ROMÁN, R. (2019). El recurso de amparo. La especial trascendencia constitucional en la jurisprudencia del Tribunal Constitucional, Valencia, Tirant lo Blanch, de próxima publicación, cuyo texto su autora ha tenido la amabilidad de adelantarme. Llamativamente, tampoco existen muchos trabajos monográficos sobre este derecho en el ámbito del Derecho procesal. Remitimos la cita a los trabajos existentes dentro de aquel campo a las notas subsiguientes del presente trabajo.

${ }^{5}$ En 2018, sobre un total de 6.721 recursos de amparo resueltos, 6.169 recibieron auto o providencia de inadmisión. Póngase este dato en relación con el que brindamos anteriormente, sobre alegación del derecho a la tutela judicial. Vid. Tribunal Constitucional. Memoria. 2018, pág. 235. 
que identifica la demanda, dirigida a un órgano judicial, de protección y restitución de los derechos e intereses de la persona lesionados en una controversia social.

Esta manera de entender el derecho a la tutela judicial puede vincularse fácilmente con la perspectiva material de interpretación del concepto procesal de acción ${ }^{6}$, como actuación dirigida a obtener una sentencia favorable para los propios derechos e intereses alegados, con la cual se ha intentado superar el formalismo del concepto formal de acción ${ }^{7}$, que identificaba a ésta con el acceso al proceso ${ }^{8}$.

Hasta ahora, no hemos hecho otra cosa que indagar sobre el contenido del derecho a la tutela judicial a partir del significado de los términos que utiliza la Constitución al reconocerlo, o, visto desde otra perspectiva, de los intereses que la Constitución ha querido proteger al incluir este derecho en su artículo 24.

Este es, también, el método que utiliza el Tribunal Constitucional al precisar el contenido de cualquier derecho fundamental. Se deriva la definición del derecho a partir del significado de los conceptos que lo constituyen, especialmente tal como los interpreta tradicionalmente la doctrina jurídica, y de los intereses a cuya realización el derecho sirve. Clásica muestra de ello es el tantas veces citado pronunciamiento del Tribunal Constitucional en la STC 11/1981 acerca de los criterios para delimitar el contenido esencial de los derechos ${ }^{9}$. Y, aunque sean operaciones diferentes la de determinar el contenido esencial de los derechos en el control de constitucionalidad de las disposiciones con fuerza de ley y la de delimitar un derecho y el alcance de sus límites a la hora de resolver un recurso de amparo ${ }^{10}$, puede decirse que, en ambos casos,

${ }^{6}$ Sobre la polémica en la doctrina del Derecho procesal acerca de los conceptos de acción, vid. DE LA OLIVA SANTOS, A. (1980). Sobre el derecho a la tutela jurisdiccional, Barcelona, Bosch, págs. 28-76, y GARBERÍ LLOBREGAT, J. (2008). El derecho a la tutela judicial efectiva en la jurisprudencia del Tribunal Constitucional, Barcelona, Bosch, págs. 12-17.

7 En general, la doctrina ha considerado el concepto material de acción más próximo a los términos en los que la Constitución reconoce el derecho a la tutela judicial efectiva. En este sentido, DE LA OLIVA SANTOS, A. (1980); ob. cit., pág. 135, GIMENO SENDRA, V. (1981). Fundamentos del Derecho procesal, Madrid, Civitas, pág. 132, y ACOSTA ESTÉVEZ, J. B. (1987). Los derechos básicos del justiciable, Barcelona, PPU.

${ }^{8}$ Algunos autores, sin embargo, se decantan por una concepción más formalista. El derecho a la tutela judicial efectiva es un derecho abstracto, que implica la obtención de una sentencia, pero sin especificar su contenido, para FIGUERUELO BURRIEZA, A. (1990); ob. cit., pág. 54. Como derecho de acceso a los órganos judiciales es configurado por MATEU-ROS CEREZO, R. (1982). «El derecho constitucional a la tutela judicial efectiva y el requisito de la legitimación», Revista de Administración Pública, 98, pág. 83. González Montes cifra el derecho a la tutela judicial en el derecho de acceso a los órganos judiciales y, en su caso, a una resolución sobre el fondo; vid. GONZÁLEZ MONTES, J. L. (1983). «Notas en torno al derecho a la tutela jurisdiccional en la Constitución Española», El Poder Judicial, Madrid, Instituto de Estudios Fiscales, pág. 1.493.

9 Nos referimos a los criterios de la recognoscibilidad del tipo abstracto del derecho en la regulación concreta y el de los intereses jurídicamente protegidos, que cita el fundamento jurídico octavo de la STC $11 / 1981$.

${ }^{10}$ Para tratar sobre la diferente aproximación del legislador y de los órganos judiciales a la interpretación de los derechos fundamentales, resulta necesario tener en cuenta la obra, ya clásica, de MEDI- 
cuando el Tribunal Constitucional define un derecho no hace sino intentar concretar lo que el derecho es, conforme a su contenido y los intereses que salvaguarda.

A nuestro parecer, las dificultades de comprensión relativas al derecho a la tutela judicial derivan de que, al tratar sobre el ámbito de este derecho, la estrategia del Tribunal Constitucional ha sido diferente, ya que su objetivo primordial no ha sido delimitar el contenido del citado derecho, sino definirlo a partir del concepto que él mismo tiene del alcance de la jurisdicción constitucional en su relación con la jurisdicción ordinaria ${ }^{11}$.

Esto explica, de antemano, el sentido de la clásica doctrina del Tribunal Constitucional según la cual el derecho a la tutela judicial efectiva no garantiza el acierto de las decisiones judiciales ${ }^{12}$. Es claro que, desde un punto de vista sustantivo, la tutela judicial efectiva solamente se alcanza a través de resoluciones judiciales acertadas, por estar articuladas mediante una adecuada interpretación y aplicación de las normas que integran el ordenamiento jurídico que esté, además, atenta a los derechos e intereses confrontados en una determinada controversia. Pero lo que el Tribunal Constitucional pretende no es, en realidad, precisar el significado de la expresión «tutela judicial», sino concretar cuál es su posición a la hora de garantizar la tutela de los derechos e intereses legítimos en relación con los demás órganos jurisdiccionales.

Así, en contraste con lo que se espera de los órganos judiciales ordinarios, que deben dar a los casos la solución que procede conforme a la normativa vigente, la función del Tribunal Constitucional será garantizar la razonabilidad del discurso judicial, al resolver una determinada controversia ${ }^{13}$.

El Tribunal Constitucional, por lo tanto, se sitúa un escalón antes de alcanzar la cima de la tutela judicial. Su función no es garantizar el acierto, sino la razonabilidad de las decisiones judiciales. Esta idea explica, por otra parte, la estructura del razonamiento del Tribunal Constitucional al resolver asuntos relativos al derecho a la tutela

\footnotetext{
NA GUERRERO, M. (1996). La vinculación negativa del legislador a los derechos fundamentales, Madrid, McGraw Hill.

${ }^{11}$ Evidentemente, la interpretación del Tribunal Constitucional sobre el derecho a la tutela judicial efectiva sin indefensión viene determinada también por el concepto y la teoría general de los derechos fundamentales. Lo que queremos decir es que esta interpretación ha venido marcada decisivamente por la intención de delimitar el campo de acción de la jurisdicción constitucional con respecto a los órganos de la jurisdicción ordinaria.

12 Conforme a la STC 209/2013, FJ 3, que resume la doctrina sobre este tema, «el art. 24.1 CE no garantiza "el acierto de la resolución adoptada en cada caso" ni excluye "eventuales errores en el razonamiento desplegado" (SSTC 68/1998, FJ 2, y 117/2006, FJ 3); asegura sólo el derecho de obtener de los órganos judiciales una resolución razonada y fundada en derecho sobre el fondo de las pretensiones oportunamente deducidas por las partes (por todas, SSTC 206/2002, FJ 2; 79/2005, FJ 2; y 19/2006, FJ 2).» En el mismo sentido, SSTC 61/2008, FJ 4, 13/2012, FJ 3, 27/2013, FJ 5, 212/2014, FJ 3, y 99/2015, FJ 3, entre otras muchas.

13 Esta exigencia de razonabilidad se plasma en diferentes tests argumentativos, dependiendo de que se aplique al acceso al proceso, a la resolución de los procesos o a la fase de ejecución, conforme veremos en el curso del presente trabajo.
} 
judicial, basada en vertientes y tests, que examinaremos posteriormente. La combinación de vertientes y tests da la medida de razonabilidad que el Tribunal Constitucional exige a las resoluciones judiciales en cada momento del proceso.

De esta forma, se explican las dificultades que muchos operadores jurídicos, especialmente Abogados, han tenido para comprender el concepto del derecho a la tutela judicial efectiva postulado por la jurisprudencia del Tribunal Constitucional. Indudablemente, resulta más difícil intuir el contenido de un concepto jurídico cuando su determinación no se deriva de la naturaleza o el contenido de dicho concepto, sino de la percepción que un órgano, el Tribunal Constitucional, tiene respecto de lo que debe ser su función con respecto al concepto en discusión. No estamos ante una aproximación sustantiva al concepto, sino ante una interpretación estructural del Tribunal Constitucional respecto de su posición en el conjunto de los órganos jurisdiccionales que garantizan el derecho a la tutela judicial.

En otros términos, el concepto del derecho a la tutela judicial que sostiene la jurisprudencia del Tribunal Constitucional ha sido creado y desarrollado por un reducido círculo de especialistas, integrado por los magistrados y letrados del Tribunal Constitucional. La doctrina así creada se separa, además, tanto del concepto comúnmente admitido en las relaciones sociales con respecto a lo que deba ser la tutela judicial, como del concepto de acción tradicionalmente discutido en el ámbito del Derecho procesal ${ }^{14}$. Por ello, la definición del derecho a la tutela judicial mantenida por el Tribunal Constitucional conlleva inevitables dificultades de comprensión, cuando es exigida a operadores jurídicos que no están comprendidos en el círculo de los especialistas que han creado dicha definición, ni en el de los expertos más familiarizados con la jurisprudencia constitucional.

Puede decirse, así pues, que existen dos conceptos de tutela judicial, que cohabitan en una relación no siempre armoniosa ${ }^{15}$. Uno, el propio del Derecho procesal, en el que la tutela judicial es la actividad de los órganos judiciales encaminada a la salvaguardia de los derechos e intereses subjetivos amparados por el ordenamiento jurídico, en situaciones en las que aquéllos se ven afectados por conflictos surgidos,

14 DE LA OLIVA SANTOS, A. (1980); ob. cit., pág. 141, GARBERÍ LLOBREGAT, V. (2002). Introducción al nuevo proceso civil, Valencia, Tirant lo Blanch, pág. 132. Varios intentos de definir el derecho a la tutela judicial efectiva desde el concepto de acción se encuentran en GIMENO SENDRA, V. (1981); ob. cit., págs. 132-133, GIMENO SENDRA, V. (2015); Introducción al Derecho Procesal, Madrid, UNED, págs. 280-288, y ALMAGRO NOSETE, J. (1983); "Comentario al art. 24 CE», en ALZAGA VILLAMIL, O.; Comentarios a las leyes políticas, Madrid, EDERSA, págs. 43 y 51.

15 Lo que se quiere decir es que son distintas las formas de comprender el derecho a la tutela judicial, dependiendo de que se examine desde una perspectiva constitucionalista o procesalista, pero, lógicamente, dichas perspectivas no operan de forma absolutamente independiente. En la práctica, hay un vínculo entre ambas. La interpretación constitucional ha de partir de las instituciones de Derecho procesal para acomodar su concepto y aplicación a su comprensión del derecho a la tutela judicial efectiva y, por otra parte, como razonaremos posteriormente, la perspectiva constitucional condiciona el desarrollo del proceso en todas sus fases. Sin embargo, la diferencia entre dichas perspectivas, en ocasiones, genera dificultades de comprensión, especialmente para el profesional ajeno a los círculos académicos. 
ya en el ámbito de las relaciones sociales, ya en el de las relaciones entre las personas y la Administración. En este marco, el órgano judicial cumple con su función de brindar tutela a los derechos e intereses de las personas proporcionando a la controversia la solución adecuada, a través de la aplicación de las normas jurídicas, y previa apreciación de la posición de cada una de las partes afectadas por el caso.

El otro es el concepto del Tribunal Constitucional, en el que el derecho a la tutela judicial efectiva se cumple cuando los órganos judiciales dan una solución razonable a los asuntos, entendiendo que dicha solución debe abarcar los momentos del acceso a la jurisdicción, de la tramitación del proceso, de la resolución del caso y de la ejecución de la sentencia firme. La exigencia de razonabilidad, como veremos posteriormente, reviste distintas formas y tiene diferente grado de exigencia, dependiendo del momento procesal, pero, en todo caso, la razonabilidad es distinta del acierto o idoneidad de la resolución judicial. La razonabilidad es una cualidad del discurso en el que se apoya el órgano judicial para argumentar su solución a cada caso, mientras que el acierto es una cualidad de la solución que el órgano judicial brinda a la controversia. Una resolución judicial puede ser razonable, si el órgano judicial aplica las normas que regulan el asunto, las interpreta conforme a criterios hermenéuticos aceptados en el ámbito jurídico y su discurso sigue un hilo lógico, aunque la solución que surja de su razonamiento pueda ser discutible en términos de acierto.

En términos sustantivos, la verdadera tutela judicial es la primera, en cuanto que va dirigida a la garantía y reparación de los derechos e intereses legítimos de las personas, tanto aquellos de naturaleza constitucional como cualesquiera otros. Lo que garantiza el Tribunal Constitucional es algo previo a la tutela judicial. Es una serie de condiciones previas, que cristalizan en varios estándares de razonabilidad, que son necesarias para que la tutela judicial de los derechos e intereses legítimos pueda ser realidad. Una decisión razonable puede o no ser acertada, pero es casi imposible que una decisión sea acertada, si no es razonable.

A primera vista, las dificultades de comprensión del contenido del derecho a la tutela judicial efectiva sostenido por la jurisprudencia del Tribunal Constitucional derivan, por tanto, de que el Tribunal Constitucional llama tutela judicial a algo que, en términos sustantivos, no lo es, sino que es una condición previa que hace posible la tutela judicial.

Hoy en día, consolidada la jurisprudencia del Tribunal Constitucional sobre el derecho a la tutela judicial, probablemente resulta más claro sostener que hay dos tutelas judiciales, una, completa y de carácter sustantivo, a la que están llamados los órganos judiciales, que deben proporcionar a cada asunto la solución más adecuada en términos jurídicos, y otra, más limitada, que lleva a cabo el Tribunal Constitucional desde una perspectiva estructural, que exige que la solución del órgano judicial se derive de una argumentación razonable. Es esta segunda acepción la que se entiende actualmente como contenido constitucional del derecho a la tutela judicial efectiva, en el cual nos centraremos a partir de este momento. 


\section{EL DERECHO A LA TUTELA JUDICIAL EFECTIVA ES UN DERECHO FUNDAMENTAL, CON TODO LO QUE ESTO COMPORTA}

Afirmar que el derecho a la tutela judicial efectiva es un derecho fundamental no supone meramente enunciar algo que es evidente mediante la lectura de la Constitución. Supone también entender que la interpretación del derecho a la tutela judicial efectiva debe ser llevada a cabo mediante técnicas hermenéuticas propias del Derecho constitucional. Precisamente, el origen de las dificultades de comprensión del contenido de este derecho reside en la confusión que aún existe entre los planos constitucional y procesal de interpretación del derecho a la tutela judicial. Y es que la aproximación al proceso del Derecho procesal y del Derecho constitucional es diferente, y distintos son también los resultados que proporciona la opción de seguir una u otra.

De entrada, en el Derecho procesal, hoy en día, se habla de la extensión del derecho a la tutela judicial a instrumentos tales como la conciliación, la mediación o la negociación ${ }^{16}$. No es esta, sin embargo, la perspectiva del Derecho constitucional. El ámbito de la resolución de las controversias amparado por el Tribunal Constitucional se limita a la llevada a cabo por los órganos judiciales, a la que hay que añadir, por su proximidad o vinculación a aquélla, el arbitraje, en la medida de la extensión efectuada por la STC 176/1996, FJ 4, y los actos preparatorios o previos necesarios para el ejercicio de la acción judicial, a través de la garantía de indemnidad (SSTC 14/1993, FJ 3, y 6/2011, FFJJ 2 y 3, entre otras ${ }^{17}$.

Algunos conceptos adoptan un sentido diferente cuando se examinan desde la perspectiva procesal o desde la constitucional. La motivación exigida a las resoluciones judiciales alcanza un grado de extensión distinto, según se examine desde una u otra óptica ${ }^{18}$. Sobre esta base, se comprende el rechazo que la doctrina del Derecho procesal muestra hacia la motivación por remisión ${ }^{19}$, que, sin embargo, es admitida por el Tribunal Constitucional con determinadas condiciones ${ }^{20}$.

${ }^{16}$ MARTÍN DIZ, F. (2019). «El derecho fundamental a justicia: revisión integral e integradora del derecho a la tutela judicial efectiva», Revista de Derecho Político, 106, págs. 17-18.

${ }_{17} \mathrm{Y}$ sin perjuicio de la ejecución forzosa de los laudos arbitrales y de los convenios de mediación, que, sin embargo, es ya competencia de los órganos judiciales. Vid. PÉREZ-UGENA COROMINA, M. (2014). «Garantía del derecho a la tutela judicial efectiva en los sistemas principales de resolución de conflictos: arbitraje y mediación», Estudios de Deusto, vol. 62/1, pág. 188.

18 Sobre este tema, resulta interesante la aproximación de IGARTUA SALAVERRÍA, J. (2003). La motivación de las sentencias, imperativo constitucional, Madrid, CEPC, págs. 21-22, para quien la obligación de motivar tiene una vertiente distinta en Derecho procesal con respecto a la del Derecho constitucional. Como precursor de esta idea, vid. TARUFFO, M. (1975). La motivazione della sentenza civile, Padua, CEDAM, págs. 370-413.

19 IGARTUA SALAVERRÍA, J. (2003); ob. cit., págs. 27-28, desde una perspectiva procesalista, rechaza la motivación per relationem. Vid. también el voto particular a la STC 116/1998, debido al magistrado Vicente Gimeno Sendra.

${ }^{20}$ La motivación por remisión se admite tanto en primera como en segunda instancia, incluyendo el procedimiento penal y el contencioso-administrativo sancionador. Vid., entre otras, SSTC 116/1998, 
De igual manera, es también diferente el concepto de indefensión manejado por la doctrinal del Derecho procesal, respecto del que emplea el Tribunal Constitucional, que requiere que la indefensión sea material, en el sentido de que repercuta de manera efectiva en las posibilidades de las partes de presentar sus alegaciones y pruebas ${ }^{21}$.

Las consideraciones anteriores permiten entender también que la jurisprudencia del Tribunal Constitucional sobre la ejecución de las resoluciones judiciales se comprenda mejor si se considera la ejecución como una fase del proceso, entendido como un iter encaminado a la salvaguardia y reparación efectiva de los derechos e intereses legítimos ${ }^{22}$, que si se entiende como un proceso autónomo, tal como hace actualmente la Ley de Enjuiciamiento Civil.

La diferente aproximación desde el Derecho constitucional explica también que el Tribunal Constitucional no acuerde indemnizaciones, como medida de reparación destinada a quien sufre una vulneración del derecho a la tutela judicial, especialmente si, a causa de ella, los derechos e intereses de la persona afectada han sufrido un perjuicio que, por el paso del tiempo, ya no es posible reparar en su totalidad ${ }^{23}$.

$Y$, como ha puesto de relieve la doctrina, la misma circunstancia explica que los conceptos formal y material de acción elaborados por la doctrina del Derecho procesal no sirvan para definir el contenido del derecho a la tutela judicial efectiva reconocido por la Constitución. No se trata de que el derecho a la tutela judicial efectiva haya sustituido al concepto de acción en su sentido procesal, sino de que hablamos de

FJ 3, 185/1998, FJ 6, 5/2002, FJ 2, 113/2004, FJ 10, 15/2005, FJ 4, 140/2009, FJ 3, 59/2011, FJ 3, y 127/2011, FJ 9. Ahora bien, la aceptación de la motivación por remisión se condiciona a que «queden debidamente exteriorizados los elementos de juicio sobre los que se basa la decisión, dado que lo relevante es que puedan conocerse las razones o criterios jurídicos que fundamentaron la decisión» (SSTC 59/2011, FJ 3, y 127/2011, FJ 9). Así, como muestra de rechazo a un caso de motivación por remisión, vid. STC 41/2007, FJ 8. Por otra parte, se requiere una motivación reforzada en algunos supuestos citados por la STC 116/1998, FJ 3, entre los que destaca la respuesta a pretensiones fundadas en una eventual lesión de derechos fundamentales (SSTC 156/2009, FJ 7, y 59/2011, FJ 3). Acerca de las peculiaridades de las resoluciones judiciales que autorizan registros domiciliarios sobre la base de lo que consta en el atestado, vid. SSTC 239/1999, FJ 6, y 205/2005, FJ 3.

${ }^{21}$ SSTC 48/1984, FJ 1, 367/1993, FJ 2, 124/1994, FJ 2, 181/2011, FJ 2, y 2/2013, FJ 9, entre otras.

22 Vid., por ejemplo, la STC 26/1983, FJ 2: «el derecho a la tutela judicial efectiva tiene un contenido complejo que incluye, entre otros, la libertad de acceso a los jueces y tribunales, el derecho a obtener un fallo de éstos y (...) también el derecho a que el fallo se cumpla y a que el recurrente sea repuesto en su derecho y compensado, si hubiere lugar a ello, por el daño sufrido».

${ }^{23}$ De hecho, queda pendiente en la doctrina la discusión sobre si las indemnizaciones pudieran ser consideradas por el Tribunal Constitucional como una de las medidas destinadas a restablecer el derecho fundamental, en el caso de que dicho restablecimiento no se pueda realizar en especie. TUR AUSINA, R. (2008). Garantía de derechos y jurisdicción constitucional. Efectividad del amparo tras la sentencia estimatoria, Valencia, Tirant lo Blanch, pág. 479, defiende la inclusión de las indemnizaciones en el ámbito del Tribunal Constitucional, si bien entiende que para ello sería necesaria una reforma de la Ley Orgánica del Tribunal Constitucional. 
realidades diferentes ${ }^{24}$. El derecho a la tutela judicial efectiva no es un mero derecho de acceso al proceso, porque ni se agota en dicha faceta, ni garantiza un acceso al proceso incondicionado, sino conforme a lo que dispongan las leyes procesales, pero tampoco es un derecho a recibir una sentencia favorable, como apuntaría la acepción coloquial o sustantiva de tutela. El derecho a la tutela judicial efectiva definido por el Tribunal Constitucional es aquel que tienen las personas a recibir una respuesta razonable de los órganos judiciales a las pretensiones de tutela de sus derechos e intereses legítimos cuando se vean afectados por controversias en las que aquéllas se encuentren involucradas en sus relaciones sociales o con la Administración, teniendo en cuenta que la exigencia de razonabilidad se plasma de diferente forma, dependiendo de la fase del proceso o de la actuación a la que se aplique.

Lo anterior nos lleva a tratar un nuevo equívoco que es habitual cuando se habla del derecho a la tutela judicial. No es posible utilizar en la interpretación de este derecho la clásica comprensión de los derechos fundamentales según la cual habría en su ámbito un contenido derivado de la Constitución y otro de creación legal, o de legalidad ordinaria, que el Tribunal Constitucional no garantizaría a través del recurso de amparo. Esta precomprensión del ámbito de los derechos sigue viva, a pesar de haberse relativizado en la propia jurisprudencia constitucional, ya sea entendiendo que el contenido adicional forma parte del contenido tutelable por el Tribunal Constitucional, como en la libertad sindical (art. 28.1 CE) ${ }^{25}$, ya sea mediante la construcción de los derechos de configuración legal, que permiten al Tribunal Constitucional amparar facultades reguladas por las leyes que se deriven del contenido de derechos fundamentales, como ocurre con el derecho al acceso a cargos y funciones públicas, tanto de carácter representativo, como no representativo (art. 23.2 CE) ${ }^{26}$.

El anterior enfoque es de tipo topográfico o espacial, en cuanto que distingue en el contenido del derecho dos zonas, la de constitucionalidad y la de legalidad ${ }^{27}$. Sin embargo, este enfoque no sirve cuando se trata de comprender el derecho a la tutela judicial efectiva, puesto que éste abarca todo el ámbito del proceso y, por tanto, todas las actuaciones que se desarrollan en aquél deben respetar el derecho a la tutela judicial $^{28}$.

${ }^{24}$ DE LA OLIVA SANTOS, A. (1980); ob. cit., pág. 141, y GARBERÍ LLOBREGAT, J. (2002); ob. cit., págs. 48-49.

${ }^{25}$ SSTC 39/1986, FJ 3, 51/1988, FJ 5, 61/1989, FJ 2, 127/1989, FJ 3, 1/1994, FJ 4, y, últimamente, en sentencias como las SSTC 152/2008, FJ 3, y 123/2018, FJ 4, entre otras.

${ }^{26}$ Vid. SSTC 47/2018, FJ 3.b), 89/2019, FJ 12, y 96/2019, FJ 3.

${ }^{27}$ Diferentes aproximaciones, a partir de este enfoque, en general, en MEDINA GUERRERO, M. (1996); ob. cit., págs. 168-172, y, en referencia al derecho a la tutela judicial efectiva, en BORRAJO INIESTA, I., DÍEZ-PICAZO GIMÉNEZ, I. y FERNÁNDEZ FARRERES, G. (1995); ob. cit., págs. 157-163, RUIZ-RICO RUIZ, G. y CARAZO LIÉBANA, M. J. (2013); ob. cit., pág. 9, y DÍEZ-PICAZO, L. M. (2013). Sistema de Derechos Fundamentales, Madrid, Thomson Civitas, 4. ${ }^{a}$ ed., pág. 118.

${ }^{28}$ Sobre los problemas del enfoque anterior, RUBIO LLORENTE, F. (1995). «El recurso de amparo constitucional», en AA. VV.; La jurisdicción constitucional en España. La Ley Orgánica del Tribunal Constitucional: 1979-1994, Madrid, CEC, pág. 164. 
El Tribunal Constitucional ha enunciado que el derecho a la tutela judicial efectiva se concreta, ante todo, en los derechos al acceso al proceso, a recibir una resolución motivada y fundada en Derecho y a la ejecución de las sentencias firmes ${ }^{29}$. Contemplado de esta forma, el derecho a la tutela judicial parece aludir a las actuaciones que se desarrollan en el inicio y el final de los procesos. Sin embargo, hay un cuarto contenido en el derecho a la tutela judicial, que es la prohibición de indefensión, que supone la exigencia de que las partes puedan alegar y probar en el curso del procedimiento cuanto les interese, en el marco de lo dispuesto por las normas procesales, y en igualdad de condiciones, salvo circunstancias extraordinarias debidamente justificadas ${ }^{30}$.

La prohibición de indefensión supone, definitivamente, que el ámbito del derecho a la tutela judicial se extiende a todo lo largo del proceso $^{31}$, ya que una buena parte de los defectos que pueden generar indefensión (la falta de asistencia de Abogado, la denegación de prueba de forma irrazonable y arbitraria, la denegación de medios de

29 SSTC 26/1983, FJ 2, 10/2000, FJ 2, 83/2001, FJ 4, 3/2004, FJ 3, 190/2005, FJ 5, 149/2006, FJ 4, por citar sólo unos ejemplos. En la doctrina, vid., en este sentido, GÓMEZ-FERRER MORANT, R (1985). «La tutela judicial efectiva como derecho fundamental», en MARTÍN-RETORTILLO BAQUER, L.; De la jurisprudencia del Tribunal Constitucional: Seminario de profesores de la Facultad de Derecho, Zaragoza, Institución «Fernando el Católico», págs. 17-23.

30 El contenido de la prohibición de indefensión está bien sintetizado en la STC 12/2011, FJ 3. Como excepción, por ejemplo, hay una desigualdad en la fase de prueba a favor de la persona trabajadora en el proceso social, cuando alega la vulneración de derechos fundamentales. Especialmente, en relación con la prohibición de discriminación, la jurisprudencia del Tribunal Constitucional señala que la parte actora debe aportar «indicios que generen una razonable sospecha, apariencia o presunción a favor de su alegato» (SSTC 136/1996, y 48/2002), y, en tal caso, se produce un desplazamiento del onus probandi, de manera que «incumbe al autor de la medida probar que su actuación obedece a motivos razonables y ajenos a todo propósito atentatorio de un derecho fundamental (SSTC 136/1996, 87/1998, 29/2000, y 114/2002, entre otras). Una síntesis de esta doctrina se encuentra en la STC 98/2003, FJ 2. La justificación de todo ello es, como se sabe, la dificultad de probar la existencia de discriminación por parte de la persona que la alega. Esta doctrina, asimismo, ha tenido reflejo en la legislación, donde se ha extendido a los órdenes civil y contencioso-administrativo. Vid. arts. 32 de la Ley 62/2003, de 30 de diciembre, de medidas fiscales, administrativas y del orden social, 13 de la Ley Orgánica 3/2007, de 22 de marzo, para la igualdad efectiva de mujeres y hombres, y 96.1 de la Ley 36/2011, de 10 de octubre, reguladora de la jurisdicción social. También se da una cierta desigualdad en la regulación del acceso a los recursos en el orden social.

31 En realidad, la discusión sobre si la prohibición de indefensión se integra en el derecho a la tutela judicial efectiva o tiene entidad propia lleva ínsito un alto grado de nominalismo, ya que está claro, a efectos prácticos, que la primera está reconocida en el artículo 24 de la Constitución. Incluyen la prohibición de indefensión como contenido del derecho a la tutela judicial efectiva autores como CHAMORRO BERNAL, F. (1994); La tutela judicial efectiva, Barcelona, Bosch, pág. 13, DÍEZ-PICAZO GIMÉNEZ, I. y FERNÁNDEZ FARRERES, G. (1995); ob. cit., pág. 158, y GARBERÍ LLOBREGAT, J. (2008); ob. cit., pág. 19. En el mismo sentido, ALONSO GARCÍA, E. (1991); «El art. 24.1 de la Constitución en la jurisprudencia del Tribunal Constitucional: problemas generales y acceso a los Tribunales», en Estudios sobre la Constitución Española. Homenaje al Profesor Eduardo García de Enterría, t. II, Madrid, Civitas, pág. 996, que detalla el contenido de este derecho en una variedad de elementos que, en su mayoría, pueden ser reconducidos al concepto de indefensión. 
alegación o defensa a una de las partes) tienen su origen en el curso de las actuaciones mediante las que se desarrolla el procedimiento ${ }^{32}$.

En fin, decir que el derecho a la tutela judicial efectiva se aplica al acceso al proceso, la motivación de las resoluciones judiciales, la ejecución y la prohibición de indefensión supone abarcar el ámbito completo del proceso. Así pues, no puede construirse el derecho a la tutela judicial efectiva delimitando espacios. Por el contrario, lo específico del derecho a la tutela judicial efectiva es la perspectiva desde la que obliga al intérprete a examinar el proceso, que es la de la razonabilidad de la actuación del órgano judicial, y no la del acierto.

Ejemplo de lo anterior es lo que ocurre con la prueba y los hechos. Aunque el Tribunal Constitucional, como principio, no debe entrar ni en la valoración de la prueba, ni en la fijación de los hechos, ha tenido que revisar resoluciones judiciales que incluyen en el relato de hechos algunos que no habían podido ser probados, precisamente, por haberse denegado previamente la prueba encaminada a tal fin ${ }^{33}$. En

32 El derecho a la tutela judicial efectiva es, además, un derecho de prestación. Vid., en este sentido, la STC 20/2012, FJ 7, y, en la doctrina, DÍEZ-PICAZO, L. (1987). «Notas sobre el derecho a la tutela judicial efectiva», Poder Judicial, 5, págs. 41-49. Sobre la jurisprudencia en torno a esta faceta del derecho a la tutela judicial, CARRASCO DURÁN, M. (2018); ob. cit., págs. 45-49. Es una perspectiva original la de Eliseo Aja, para quien el derecho a la tutela judicial efectiva es un derecho fundamental en sí y garantía de los demás derechos e intereses legítimos reconocidos por las leyes, un derecho de prestación y valor o principio general del ordenamiento, lo que se resume en «la correcta resolución de los conflictos planteados» ante los órganos judiciales; cfr. AJA, E. (1991). «Prólogo», en RUIZ RUIZ, G.; El derecho al juez ordinario en la Constitución española, Madrid, Civitas. Otras facetas de este derecho, en GONZÁLEZ PÉREZ, J. (1984). El derecho a la tutela jurisdiccional, Madrid, Civitas, pág. 28, y ALBÁCAR LÓPEZ, J. L. (1983); «Contenido y alcance del derecho a la tutela jurisdiccional», El Poder Judicial, Madrid, Instituto de Estudios Fiscales, pág. 418.

33 Las «estrechas relaciones» o la «inescindible conexión» del derecho a utilizar los medios de prueba pertinentes para la defensa del artículo 24.2 de la Constitución y el derecho a la tutela judicial efectiva del apartado primero del mismo artículo ha sido reconocida en sentencias tales como las SSTC 19/2001, FJ 4, 133/2003, FJ 3, 3/2004, FJ 6, y 212/2013, FJ 4, por una parte, y 37/2000, FJ 3, y $133 / 2013$, FJ 3, por otra. La doctrina sobre el derecho a utilizar los medios de prueba está bien sintetizada en las SSTC 86/2008, FJ 3, y 130/2017, FJ 2, entre otras, y no sólo es aplicable al proceso penal, sino también al contencioso-administrativo (SSTC 133/2003 y 3/2004) y al procedimiento disciplinario penitenciario (STC 185/2007). La función del Tribunal Constitucional en relación con la actividad probatoria es descrita en las SSTC 159/2004, FJ 9, 129/2005, FJ 9, y 16/2016, FJ 5, entre otras. Con respecto a cómo repercute la denegación de una prueba en el relato de hechos probados de la sentencia, vid. STC 128/2017, FJ 4. La denegación de una prueba y la posterior desestimación de una pretensión basada en que no han quedado probados los hechos sobre los que aquélla versaba es causa de arbitrariedad de la correspondiente resolución (STC 3/2004, FJ 6). Las controversias relativas la valoración de la prueba en el proceso penal son reconducidas normalmente al derecho a la presunción de inocencia, aunque en la jurisprudencia sobre el tema se deja sentir la exigencia de un canon de motivación más riguroso (STC 12/2011, FJ 9). Las relaciones entre ambos derechos están bien examinadas en RUIZ-RICO RUIZ, G. y CARAZO LIÉBANA, M. J. (2013); ob. cit., pág. 22; ALONSO GARCÍA, E. (1991); ob. cit., págs. 994 y ss., y MORENO CATENA, V. y otros (1988). Derecho Procesal, t. I, vol. I, Valencia, Tirant lo Blanch, pág. 164.Otros autores intentan diferenciar ambos derechos desde diferentes perspectivas. Entre estos, DÍEZ-PICAZO, L. M. (2013); ob. cit., pág. 404, y CHAMORRO BERNAL, F. 
fin, todo el proceso es revisable desde el canon del derecho a la tutela judicial efectiva, especialmente cuando aquél se concreta en la necesidad de que las resoluciones judiciales estén motivadas y no sean irrazonables, ni arbitrarias, ni contengan error patente ${ }^{34}$.

\section{EL JUICIO DE RAZONABILIDAD: VERTIENTES Y TESTS}

El problema se plantea cuando hay que precisar en qué consiste el juicio de razonabilidad del que depende que una resolución sea o no conforme con el derecho a la tutela judicial efectiva. Para evaluar esto, el Tribunal Constitucional ha desarrollado una argumentación basada en vertientes y tests ${ }^{35}$. Es decir, el derecho a la tutela judicial efectiva se subdivide en una serie de vertientes y a cada vertiente se le aplican uno o varios tests.

De esta forma, el derecho de acceso al proceso se descompone en las vertientes de acceso a la jurisdicción, de acceso a los recursos legalmente previstos y de garantía de indemnidad. La primera se desarrolla en el acceso a la primera instancia, la segunda, en el acceso a sucesivas instancias conforme a lo dispuesto en la normativa procesal ${ }^{36}$, y la tercera supone una garantía de que la persona demandante no sufrirá ninguna consecuencia lesiva en sus derechos en el ámbito laboral por haber demandado a su empleador ${ }^{37}$.

El derecho a una resolución motivada y fundada en Derecho supone en sí una vertiente de la que pueden entresacarse dos garantías -la de una resolución motivada ${ }^{38}$

(1994); ob. cit., págs. 126 y 390. Sobre la importancia procesal de distinguir entre ambos derechos, CARRASCO DURÁN, M. (2018); ob. cit., pág. 65.

${ }^{34}$ En el mismo sentido, VIVER PI-SUNYER, C. y LÓPEZ BOFILL, C.; (2006). «Derecho a la tutela judicial efectiva sin indefensión», en VIVER PI-SUNYER, C. (Coord.); Jurisdicción constitucional y judicial en el recurso de amparo, Valencia, Tirant lo Blanch, pág. 155.

35 Un antecedente del examen del derecho a la tutela judicial efectiva articulado sobre vertientes y tests se encuentra en VIVER PI-SUNYER, C. y LÓPEZ-BOFILL, C. (2006); ob. cit., págs. 23-25.

${ }^{36}$ Como excepción, Pérez Royo entiende que el derecho a la doble instancia es un derecho constitucional, que sólo podría ser excepcionado por el legislador en determinados casos, vid. PÉREZ ROYO, J. (2018); Curso de Derecho Constitucional, Madrid, Marcial Pons, 16. a ed., pág. 380.

37 Sobre la garantía de indemnidad, vid. STC 6/2011, FFJJ 2 y 3. Esta sentencia introduce una faceta objetiva en la garantía de indemnidad, que permite al trabajador reaccionar frente a perjuicios que sufran en el curso de su relación de trabajo, aunque no haya voluntariedad por parte del empleador. La prueba de los perjuicios, en lo relativo a la garantía de indemnidad, se articula a través de la prueba indiciaria, como pone de relieve la STC 183/2015, FJ 4.

38 Así, para la STC 183/2011, FJ 5, «la resolución ha de estar motivada, es decir, contener los elementos y razones de juicio que permitan conocer cuáles han sido los criterios jurídicos que fundamentan la decisión». En el mismo sentido, «el pronunciamiento del órgano judicial ha de ser la conclusión de una argumentación ajustada al tema o temas en litigio, para que los interesados, los órganos judiciales superiores, en su caso, y también los ciudadanos, puedan conocer el fundamento, la ratio decidendi de las resoluciones, evitando incurrir en la tacha de arbitrariedad, que hemos caracterizado como una actuación judicial sin razones formales ni materiales y que resulta de una "simple expresión de la 
y la de una resolución fundada en Derecho ${ }^{39}$ - que se escalonan en una graduación de exigencia progresiva.

El derecho a la ejecución de las sentencias se subdivide en la vertiente o derecho a la ejecución de las sentencias firmes en sus propios términos y en la vertiente o derecho a la intangibilidad de las resoluciones judiciales firmes. La primera supone la garantía de que las sentencias firmes serán ejecutadas, mientras que la segunda, que se identifica con el efecto de cosa juzgada material, significa que, en el curso de la ejecución, no se cambiará la decisión adoptada en el fallo de la resolución judicial ${ }^{40}$.

Finalmente, la prohibición de indefensión comporta, en primer lugar, una vertiente, a veces denominada como derecho de defensa o derecho a no padecer indefensión ${ }^{41}$, que integra garantías como las relativas a la igualdad de las partes en el proceso, a la aportación de medios de prueba que no puedan considerarse razonablemente como faltos de pertinencia y a la asistencia de Abogado. Estas dos últimas garantías resultan difíciles de deslindar con respecto a las de similar significado contenidas en

voluntad" o de un "mero voluntarismo judicial" (por todas, SSTC 160/1997, FJ 7; 82/2002, FJ 8; y 164/2002, FJ 4)» (STC 29/2010, FJ 4). La motivación debe ser suficiente para conocer cuáles han sido los criterios jurídicos esenciales fundamentadores de la decisión y debe responder tanto a las alegaciones como a las pretensiones, pero no es necesario que sea exhaustiva y pormenorizada, por lo que basta una motivación concisa, una respuesta global a las alegaciones e, incluso, una motivación tácita, sobre todo cuando se trata de la respuesta a las alegaciones (SSTC 187/1989, FJ 3, 14/1991, FJ 4, 87/1994, FJ 4, 171/2002, FJ 2, y 25/2012, FJ 4, así como la STEDH de 9 de diciembre de 1994, asuntos Hiro Balani c. España y Ruiz Torija c. España). Conforme a la STC 8/2014, FJ 4, «el canon constitucional de la "motivación suficiente" no se ve satisfecho mediante la simple exposición de una conclusión, fáctica o jurídica, sino que requiere un razonamiento o inferencia: en aquel caso (factum) la plasmación de una valoración probatoria, y en éste (ius), la presentación de las correspondientes premisas jurídicas (ratio decidendi), presupuestos de la conclusión decisoria (decisum). En este sentido, la STC 184/1992, FJ 2, señala que una resolución judicial vulnera el derecho a la tutela judicial cuando «contiene contradicciones internas o errores lógicos que hacen de ella una resolución manifiestamente irrazonable por contradictoria y, por ello, carente de motivación». Y la STC 183/2011, FJ 5, señala que «en todo caso, no cabe admitir como decisiones motivadas y razonadas aquellas que, a primera vista y sin necesidad de mayor esfuerzo intelectual y argumental, se comprueba que parten de premisas inexistentes o patentemente erróneas o siguen un desarrollo argumental que incurre en quiebras lógicas de tal magnitud que las conclusiones alcanzadas no pueden considerarse basadas en ninguna de las razones aducidas (por todas, SSTC 214/1999, FJ 4; 96/2006, FJ 6; 105/2009, FJ 2; y 64/2010, FJ 3).»

39 Para la STC 183/2011, FJ 5, «este último aspecto no incluye un pretendido derecho al acierto judicial en la selección, interpretación y aplicación de las disposiciones legales, salvo que con ellas se afecte al contenido de otros derechos fundamentales distintos al de tutela judicial efectiva. Pero la fundamentación en Derecho sí conlleva la garantía de que la decisión no sea consecuencia de una aplicación arbitraria de la legalidad, no resulte manifiestamente irrazonada o irrazonable o incurra en un error patente ya que, en tal caso, la aplicación de la legalidad sería tan sólo una mera apariencia (SSTC 24/1990, FJ 4; 58/1997, FJ 2; 147/1999, FJ 3; 87/2000, FJ 3; 82/2001, FJ 2; 221/2001, FJ 6; 55/2003, FJ 6; 119/2003, FJ 3; 196/2003, FJ 6; y 223/2005, FJ 3, entre otras muchas).»

40 SSTC 171/1991, FJ 3, 17/2008, FJ 3, y 20/2010, FJ 4, entre otras.

41 Sobre el concepto de indefensión derivado de la jurisprudencia constitucional, vid. BORRAJO INIESTA, I., DÍEZ-PICAZO, I. y FERNÁNDEZ FARRERES, G. (1995); ob. cit., págs. 103-117. La expresión derecho de defensa se utiliza con más frecuencia para designar una de las garantías del artículo 24.2 de la Constitución.

(C) UNED. Revista de Derecho Politico 
el apartado segundo del artículo 24. En nuestra opinión, y siguiendo a Chamorro Bernal, podría establecerse un criterio de distinción conforme al cual estaríamos ante un caso de indefensión cuando alguna de las partes sufriera una privación absoluta de alguna de dichas garantías, mientras que estaríamos en sede del artículo 24.2 de la Constitución cuando en el desarrollo de la prueba o de la asistencia de Abogado se produjeran defectos que frustraran la finalidad del reconocimiento constitucional de tales garantías ${ }^{42}$.

Lo característico de esta vertiente es que se define por un resultado -la indefensión- más que por una concreta facultad ${ }^{43}$. Este factor, de índole finalista, hace también que, en ocasiones, se solape con otras vertientes en una relación de causa a efecto. Esto es algo que se produce, especialmente, en situaciones en las que se encuentra en juego el acceso al proceso por la parte demandada. En tales circunstancias, la vertiente del derecho afectada será el derecho de acceso a la jurisdicción o la prohibición de indefensión, dependiendo de que se ponga el énfasis en la facultad ejercida por la parte, o en el resultado derivado de no habérsele dejado ejercer tal facultad. Por ello, es común que la jurisprudencia cite ambas vertientes de forma simultánea.

Además, se integran en el concepto genérico de indefensión algunas vertientes específicas, como las relativas a incongruencia y a reforma peyorativa ${ }^{44}$. Incluso, podría incluirse el derecho a una resolución judicial conforme con el sistema de fuentes, que tiene suficiente entidad como para ver en ella una vertiente diferenciada, aunque el Tribunal Constitucional no la haya considerado aún como tal ${ }^{45}$.

42 Sobre este tema, CHAMORRO BERNAL, F. (1994); ob. cit., págs. 126 y 390.

43 CARRASCO DURÁN, M. (2018); ob. cit., págs. 307-315.

${ }_{44}$ Con respecto a la incongruencia, la STC 25/2012, FJ 3, recopila la jurisprudencia y describe detalladamente el concepto y los tipos. En especial, para que se dé incongruencia por exceso, ya como incongruencia ultra petitum o extra petitum, es necesario que el Tribunal Constitucional aprecie indefensión en el caso (STC 9/1998, FJ 2). Para el concepto de reforma peyorativa, nos remitimos a las SSTC 45/1993, FJ 2, 203/2007, FJ 2, y, especialmente, 223/2015, FJ 2. La prohibición de reforma peyorativa es válida en todos los procesos, pero adquiere especial relevancia en el proceso penal. En éste, ha sido encuadrada por el Tribunal Constitucional en varias categorías, siempre con el resultado de considerar vulnerado el derecho del art. 24.1 CE. Así, por ejemplo, la STC 45/1993, FJ 3, la entiende como una modalidad de indefensión prohibida por el artículo 24.1 CE, derivada de una modalidad de incongruencia procesal, la STC 204/2007, FJ 4, la considera una modalidad de incongruencia extra petita, la STC 28/2003, FJ 3, con cita de varias sentencias, se centra en la vulneración de la interdicción de indefensión que incluye el derecho a la tutela judicial efectiva, y la STC 223/2015, genéricamente, considera que este vicio da lugar a una vulneración del derecho a la tutela judicial efectiva.

45 De acuerdo con la STC 23/1988, FJ 1, «la tutela judicial efectiva, a la que todos tienen derecho, entraña, como presupuesto implícito e inexcusable, la necesidad de que los juzgadores resuelvan secundum legem y ateniéndose al sistema de fuentes establecido». Igualmente, resulta ilustrativa la cita sobre esta materia de la STC 90/1990, FJ 4. Los casos de quiebra del sistema de fuentes que merecen la reacción del Tribunal Constitucional se producen cuando: a) un órgano judicial opta por resolver haciendo caso omiso de una ley aplicable, con el argumento de que dicha ley es contraria a la Constitución, y sin presentar previamente la cuestión de inconstitucionalidad (STC 23/1988, FJ 1); b) el órgano judicial opta por hacer caso omiso de una ley, con el argumento de que es contraria a una norma de Derecho de la Unión Europea, sin presentar previamente la correspondiente cuestión prejudicial en los supuestos en 
El Tribunal Constitucional alterna ocasiones en las que encuadra los casos expresamente en alguna de dichas vertientes con otras en que no hace uso de tales vertientes en su argumentación, pero incluso en estas últimas la referencia a las distintas vertientes integrantes del derecho a la tutela judicial se vislumbra de manera tácita. Ahora bien, lo más relevante, a efectos de poner forma a la aproximación del Tribunal Constitucional al proceso, es distinguir los tests que aquél utiliza para determinar cuándo se produce una lesión del derecho a la tutela judicial efectiva ${ }^{46}$.

El test básico, a estos efectos, comporta la exigencia de que las resoluciones judiciales sean motivadas y no incurran en arbitrariedad, irrazonabilidad o error patente ${ }^{47}$. Este es el test generalmente aplicable cuando no proceda aplicar alguno de los siguientes tests específicos.

los que aquélla es preceptiva (STC 58/2004, FJ 10, y 194/2006, FJ 5, cuya doctrina ha sido concretada posteriormente en su aplicación por otras sentencias); c) el órgano judicial hace caso omiso de una norma de Derecho de la Unión Europea o de jurisprudencia del Tribunal de Justicia de la Unión Europea aplicable al caso sin presentar previamente la cuestión prejudicial (SSTC145/2012, FJ 6, 232/2015, FJ 4, y 75/2017, FJ 3). Se incluye en estos el supuesto en que el órgano judicial no cumple lo dispuesto en una sentencia previa del Tribunal de Justicia de la Unión Europea. También han sido objeto de este tratamiento los casos en que un órgano judicial decide resolver haciendo caso omiso de una ley de una Comunidad Autónoma aplicable, dando prevalencia a una ley básica del Estado contradictoria con aquélla, sin presentar la cuestión de inconstitucionalidad con respecto a la primera, que, sin embargo, recientemente han sido aceptados por aquél como aplicación de la cláusula de prevalencia del artículo 149.3 de la Constitución (SSTC 102/2016 y, especialmente, 204/2016, que ha extendido la solución basada en la cláusula de prevalencia).

46 VIVER PI-SUNYER, C. y LÓPEZ BOFILL, C. (2006); ob. cit., págs. 24-25, distinguen los siguientes tests: error patente, congruencia, motivación (en sus vertientes de existencia de motivación, motivación suficiente - desde el punto de vista lógico o desde el punto de vista jurídico- y motivación reforzada), proporcionalidad (sobre todo, al aplicar el principio pro actione), arbitrariedad y razonabilidad (en diferentes versiones) y corrección jurídica o legalidad ordinaria, que se utiliza de manera esporádica.

${ }^{47}$ La distinción entre el concepto de arbitrariedad y el de irrazonabilidad resulta muy sutil. De hecho, el Tribunal Constitucional, muchas veces, utiliza ambos sin distinguir su significado. Para la STC 41/2007, FJ 5, «la arbitrariedad debe entenderse como un actuar judicial sin razones formales ni materiales y que resulta de una simple expresión de la voluntad (STC 51/1982, FJ 3; STC 164/2002, FJ 4). A su vez la irrazonabilidad se produce cuando el razonamiento incurre en quiebras lógicas de tal magnitud que las conclusiones alcanzadas no pueden considerarse basadas en ninguna de las razones aducidas (STC 214/1999, FJ 4; 164/2002, FJ 4).» Sobre el vicio de irrazonabilidad, asimilado a quiebras lógicas, SSTC 191/2011, FJ 6, y 133/2013, FJ 5. La irrazonabilidad se asimila a la ausencia de motivación en las SSTC 184/1992, FJ 2, 3/2004, FJ 4, y 183/2011, FJ 5. El criterio de razonabilidad adquiere matices distintos en relación con la prueba, STC 16/2016, FJ 5. El concepto de arbitrariedad se examina conectado con la noción de «voluntarismo judicial» en las SSTC 29/2010, 189/2011 y 133/2013, entre otras, o bien, con otros matices, en las SSTC 186/2002, FJ 5, y 61/2008, FJ 4. Asimismo, vulneran el derecho a la tutela judicial las resoluciones judiciales que se fundamentan en «error notorio y manifiesto, que sea apreciable en sí mismo como tal, sin más análisis o razonamiento», siempre que «no entrañ(e) clase alguna de juicio valorativo de los hechos» (STC 77/1994, FJ 2, entre otras). Por ejemplo, errores en cálculos matemáticos, en la identificación de una persona o de un bien, omisión de escritos que constan en los autos como presentados, etc. La doctrina actual sobre el error patente ha sido bien detallada por las SSTC 167/2008, FJ 2, y 167/2014, FJ 6. Para más jurisprudencia sobre estos temas, vid. la nota 33 del presente trabajo.

(C) UNED. Revista de Derecho Politico

N. ${ }^{\circ} 107$, enero-abril 2020, págs 13-40 
El test del principio pro actione sólo permite resoluciones de inadmisión «cuando encuentren amparo en una norma legal interpretada y aplicada razonablemente y sin rigorismo, formalismo excesivo o desproporción ${ }^{48}$.» No supone que las demandas deban ser admitidas en todo caso, ni la necesidad de forzar la interpretación de las normas más allá del sentido de sus términos, pero exige a las decisiones de inadmisión algo que va más allá de la mera adecuación al texto de la norma y que conduce a la necesidad de interpretar aquélla de manera que se facilite la admisión, siempre que esta solución quepa en el significado de la propia norma

El test del principio pro actione supone la traslación del principio de proporcionalidad al ámbito de la tutela judicial ${ }^{49}$ y se aplica cuando entra en juego la vertiente de acceso a la jurisdicción y la de ejecución de las resoluciones judiciales firmes, esta última en cuanto supone el acceso de la parte interesada al proceso o trámite conducente a dar ejecución a la resolución obtenida como colofón del proceso ${ }^{50}$. Por el contrario, al evaluar resoluciones de inadmisión de recursos, el test aplicable es el de resolución motivada y sin arbitrariedad, irrazonabilidad o error patente, de manera que cualquier interpretación de la normativa que regula el acceso a la segunda instancia es aceptable, incluso aunque conlleve la inadmisión, siempre que cumpla este último test, que tiene carácter más liviano ${ }^{51}$.

El test de motivación reforzada se aplica a varios supuestos que ha detallado la STC 116/1998 ${ }^{52}$. En especial, el órgano judicial debe explicar suficientemente aquellas decisiones que afectan a derechos fundamentales sustantivos ${ }^{53}$. Particularmente,

48 STC 44/2013, FJ 4. En el mismo sentido, SSTC 3/2004, FFJJ 3 y 5, 75/2008, FJ 2, 25/2010, FJ 3, y 71/2010, FJ 3

49 STC 22/2011, FJ 5. Si bien en estos casos el juicio de proporcionalidad no sigue la tradicional subdivisión en los tres juicios de idoneidad, necesidad y proporcionalidad en sentido estricto, sino que queda vinculado al rechazo a toda interpretación «excesivamente formal o rigorista» (STC 194/2013, FJ 6). En el mismo sentido, STC 71/2010, FJ 3.

50 SSTC 33/1987, FJ 3, 151/1993, FJ 4, 194/1993, FJ 3, y 106/2013, FJ 4. En el mismo sentido, SSTC 5/2009 y 10/2012. Igualmente, la STC 32/2005, que entiende que la misma doctrina es aplicable a efectos de valorar la concurrencia de la excepción de litispendencia.

51 Por todas, STC 204/2012, FJ 2.

52 De acuerdo con la STC 116/1998, FJ 4, «deben tenerse en cuenta los varios supuestos en los que este Tribunal ha venido exigiendo un específico, y reforzado, deber de motivar las resoluciones judiciales, en tanto que exigencia directamente derivada de la Constitución. Tal cosa ocurre cuando se ven afectados otros derechos fundamentales (SSTC 86/1995, 128/1995, 62/96, 170/1996, 175/1997 o 200/1997); cuando se trata de desvirtuar la presunción de inocencia, en especial a la luz de pruebas indiciarias (SSTC 174/1985, 175/1985, 160/1988, 76/1990, 134/1996 o 24/1997); cuando se atañe "de alguna manera a la libertad como valor superior del ordenamiento jurídico" (STC 81/1997, fundamento jurídico 4, que cita la STC 2/1997); o, en fin, cuando el Juez se aparta de sus precedentes (SSTC 100/1993 y 14/1993).»

53 Conforme a la STC 96/2012, FJ 9, «las exigencias de justificación y motivación de la medida se ven reforzadas cuando se está limitando el contenido de un derecho fundamental, exigencias que no se satisfacen con cualquier forma de motivación que permita conocer la ratio decidendi de la resolución judicial, pues el deber de motivación de las resoluciones judiciales limitativas de los derechos fundamentales "no encuentra su fundamento constitucional en la genérica obligación de motivación de todas 
esto supone la exclusión de «cláusulas de estilo, vacías de contenido preciso, tan abstractas y genéricas que pueden ser extrapoladas a cualquier otro caso ${ }^{54}$ », que no permitan conocer los criterios esenciales que fundamenten la resolución recaída, ni discernir si el asunto ha sido realmente examinado por el órgano judicial.

En estos casos, el criterio más comúnmente usado por el Tribunal Constitucional consiste en entender que se ha producido la vulneración de dos derechos fundamentales, el relativo a la tutela judicial y el derecho sustantivo ${ }^{55}$.

Junto a los anteriores, que son los más habituales, pueden deducirse otros tests específicos. Entre ellos, citaremos los que exigen que la indefensión sufrida tenga carácter material y no meramente formal, en el sentido de que afecte de manera real a las posibilidades de defensa de la parte y no haya sido provocada por la parte que la alega $^{56}$; el test de proporcionalidad, que se ha aplicado, especialmente al hilo del principio pro actione, de manera genérica, y sin su típico desglose en los tres juicios de adecuación o idoneidad, necesidad y proporcionalidad en sentido estricto ${ }^{57}$; el test de congruencia $^{58}$, que incorpora la exigencia de indefensión en los casos en que se alegue incongruencia por exceso ${ }^{59}$; el test de efectividad de las actuaciones judiciales, que tiene especial aplicación para exigir que los emplazamientos lleguen a conocimiento

las resoluciones judiciales que resulta del derecho a la tutela judicial efectiva (art. 24.1, en relación con el art. 120.3 CE)", sino en la protección del derecho sustantivo, lo que implica que "la ausencia de motivación ocasiona, por sí sola, en estos casos la vulneración del propio derecho fundamental sustantivo (SSTC 128/1995 y 158/1996, 181/1995 y 54/1996), todo ello sin perjuicio de que se produzca o no, además, la lesión del derecho a la tutela judicial efectiva (STC 158/1996)” (STC 207/1996, FJ 4).» Vid. también las SSTC 87/2000, FJ 6, 32/2011, FJ 6, y 31/2013, FJ 3.

54 SSTC 177/1994, FJ 2, 26/1997, FJ 3, 116/1998, FJ 3, y 185/1998, FJ 5, en sentencias relativas a recursos de apelación en materia penal. Especialmente, se rechaza el uso de formularios en casos relativos a derechos fundamentales. Vid. SSTC 116/1998, FJ 4, y 156/2009, FJ 7, esta última en el recurrente caso de resoluciones en materia penitenciaria.

55 SSTC 96/2009, FJ 9, 37/2011, FJ 7, y 96/2012, FJ 11, entre otras.

56 SSTC 48/1984, FJ 1, 367/1993, FJ 2, 124/1994, FJ 2, y 181/2011, FJ 2.

57 Vid., por todas, STC 194/2013, FJ 6. El test de proporcionalidad queda asimilado al rechazo a todo rigorismo o formalismo excesivo en la apreciación de causas de inadmisión.

58 Como se expresa en las SSTC 29/1987, FJ 2, y 198/1992, FJ 2, la incongruencia «sólo se dará cuando las resoluciones judiciales alteren de modo decisivo los términos en que se desarrolle la contienda, sustrayendo a las partes el verdadero debate contradictorio, propuesto por ellas, con merma de sus posibilidades y derecho de defensa y produciéndose un fallo o parte dispositiva no adecuado o no ajustado sustancialmente a las recíprocas pretensiones de las partes. Pero si el ajuste es sustancial y se resuelven, aunque sea genéricamente, las pretensiones, no existirá incongruencia, pese a que no haya pronunciamiento respecto de alegaciones concretas no sustanciales.» Para otras referencias, vid. la nota 39 del presente trabajo.

59 Por todas, STC 9/1998, FJ 2.

(C) UNED. Revista de Derecho Politico

N. ${ }^{\circ} 107$, enero-abril 2020, págs $13-40$ 
de sus destinatarios ${ }^{60}$; el test de prohibición de reforma peyorativa ${ }^{61}$, y el test de non bis in idem ${ }^{62}$, aplicables estos tres últimos en el ámbito de la prohibición de indefensión.

Además, existen unos tests auxiliares, consistentes en criterios hermenéuticos que ayudan a la aplicación de los tests anteriores y sirven para concretar las consecuencias de su aplicación. Uno de estos tests aconseja tener en cuenta las circunstancias del caso o el contexto de las personas afectadas ${ }^{63}$, de manera que resulta evidente su vinculación con la búsqueda de la justicia material. En otros casos, la jurisprudencia impone una interpretación finalista de las normas ${ }^{64}$. Estos tests, ciertamente, merecen una doble valoración. Por una parte, constituyen instrumentos que permiten una mayor flexibilidad a la hora de adecuar la solución a las especificidades de casos concretos, pero, por otra, incorporan un grado de incertidumbre, ya que no puede fijarse una regla clara que permita deducir cuándo serán aplicados.

En todo caso, la clave para comprender la aplicación del derecho a la tutela judicial efectiva reside en tener en mente el mecanismo de vertientes y tests. En el discurso sobre el derecho a la tutela judicial efectiva, que, como hemos señalado anteriormente, versa, en líneas generales, sobre la razonabilidad de las resoluciones judiciales, los tests aportan la medida de razonabilidad que se exige a dichas resoluciones, que puede ser diferente, dependiendo de la vertiente en la cual se deba encuadrar el caso, así como de otras circunstancias atinentes al propio caso.

${ }^{60}$ SSTC 326/1993, FJ 5, 155/1994, FJ 2, y 3/2010, FJ 2. No podemos detallar la extensa casuística que integra este supuesto, pero sí señalar que, como es conocido, esta doctrina ha servido para excluir los emplazamientos por edicto, salvo casos excepcionales. En este sentido, vid. SSTC 367/1993, FJ 2, 51/1994, FJ 3, 28/2010, FJ 4, 61/2010, FJ 3, 197/2013, FFJJ 2 y 3, 30/2014, FJ 3, entre otras. La necesidad de evitar el emplazamiento mediante edicto adquiere especial relevancia «en aquellos supuestos en que del proceso podían derivarse perjuicios para el interesado o cuando el procedimiento en sí colocaba de suyo a la parte demandada en una especial posición frente a quien les demandaba» (STC 197/2013, FJ 3). Esto es así, especialmente, en los procesos de ejecución (SSTC 219/1999, FFJJ 3 y 4 , 28/2010, FJ 4, 43/2010, 122/2013, FJ 4, 190/2014, FJ 2, y 50/2017, FJ 3, que llega a sugerir al órgano judicial la búsqueda del domicilio de la persona afectada por internet si su domicilio se encuentra en el extranjero, antes que recurrir a la citación por edicto) y en expedientes de jurisdicción voluntaria (STC 61/2010, FFJJ 2 y 3, y 155/2011, FJ 3).

${ }^{61}$ Vid. la nota 39 del presente trabajo.

${ }^{62}$ La prohibición de non bis in idem ha sido deducida, normalmente, del principio de legalidad del artículo 25 de la Constitución [SSTC 2/2003, FJ 6, y 86/2017, FJ 5.D)], pero existen casos en los que se extrae del derecho a la tutela judicial. Vid. la STC 69/2010, FFJJ 3 y 4.

${ }_{63}$ STC 183/2011, FJ 5, 167/2015, FJ 4, y 16/2016, FJ 10.

${ }^{64}$ SSTC 344/1993, FJ 2, y 100/1995, FJ 2. Igualmente, la interpretación finalista viene implícita, por ejemplo, en la jurisprudencia que exige la efectividad de los emplazamientos o en aquella que requiere que la indefensión tenga carácter material. 


\section{CONCLUSIONES Y CRÍTICA}

Tres conclusiones se pueden extraer del trabajo que hemos desarrollado. La primera es que el derecho a la tutela judicial efectiva entraña dificultades cuando se trata de explicarlo en términos comprensibles a operadores jurídicos ajenos al círculo de quienes elaboran y estudian en el ámbito académico la jurisprudencia del Tribunal Constitucional. Ello se debe a que la tutela judicial, en términos sustantivos, es la protección de los derechos e intereses legítimos, y, en esta lógica, exige el acierto de las resoluciones judiciales en su tarea de interpretación y aplicación de las normas. El concepto de tutela judicial construido por la jurisprudencia del Tribunal Constitucional no exige, sin embargo, el acierto en las resoluciones judiciales, sino que se basa en un examen de la razonabilidad del discurso que sustenta dichas resoluciones. La razón que fundamenta dicha construcción ha sido el interés del Tribunal Constitucional por definir, desde un punto de vista estructural, su relación con los demás órganos jurisdiccionales.

Como segunda conclusión, no es correcto delimitar el contenido del derecho a la tutela judicial efectiva desde la clásica dinámica «topográfica» de distinguir un contenido propiamente constitucional y otro de desarrollo legal. El derecho a la tutela judicial efectiva y sin indefensión abarca todas las actuaciones judiciales desarrolladas en el curso del proceso. No se puede aislar ningún ámbito de actuaciones judiciales de la influencia de la interpretación constitucional del derecho a la tutela judicial. Lo que caracteriza al derecho a la tutela judicial efectiva, más bien, es el punto de vista desde el que fuerza a examinar las actuaciones judiciales a quien desee utilizar este derecho como fundamento de su argumentación. Esta perspectiva, como se ha dicho, requiere valorar, no el acierto, sino la razonabilidad del discurso del órgano judicial.

Finalmente, esta construcción del derecho a la tutela judicial efectiva ha generado una particular estructura en la argumentación destinada a delimitar este derecho. Ciertamente, el derecho a la tutela judicial se puede descomponer en cuatro derechos, como son los relativos al acceso al proceso, a una decisión judicial motivada y fundada en Derecho, a la ejecución de las resoluciones firmes y a no sufrir indefensión. Sin embargo, esta descripción poco dice del derecho a la tutela judicial, ya que no hace sino afirmar que este derecho se aplica a la totalidad del proceso.

De ahí que la jurisprudencia actual articule el discurso acerca del derecho a la tutela judicial sobre una distinción de varias vertientes (acceso a la jurisdicción, acceso a los recursos legalmente previstos, garantía de indemnidad, resolución motivada y fundada en derecho, ejecución de sentencias en sus términos, intangibilidad de las resoluciones judiciales firmes, derecho a no padecer indefensión o derecho de defensa, incongruencia, reforma peyorativa) a las que se aplican varios tests (exigencia de que la resolución esté motivada y no sea irrazonable, ni arbitraria, ni adolezca de error patente; principio pro actione; motivación reforzada cuando se trata de derechos fundamentales sustantivos; congruencia; proporcionalidad; efectividad de los emplaza- 
mientos; indefensión material; prohibición de reforma peyorativa; non bis in idem; interpretación conforme a las circunstancias o el contexto; interpretación finalista). Estos tests marcan la medida de la razonabilidad que es exigible a las resoluciones judiciales. Una medida que es variable, dependiendo del grado de rigor de cada test, de la vertiente a la que se aplique y de las circunstancias del caso.

La crítica a esta construcción del derecho a la tutela judicial viene de suyo. El intento de precisar un derecho a partir de la razonabilidad parece conllevar una petición de principio, puesto que, de manera intrínseca, toda argumentación a partir de lo que es o no razonable nos asegura un grado de vaguedad, cuando no de subjetivismo ${ }^{65}$.

Sin embargo, cabe preguntarse si es mejor la alternativa. En este sentido, no cabe duda de que la delimitación del derecho a la tutela judicial como un mero derecho de acceso a los órganos judiciales, como ocurre en la Ley Fundamental alemana y ha defendido un sector de nuestra doctrina ${ }^{66}$, ayudaría a delimitar mejor el ámbito de este derecho, pero, al mismo tiempo, conllevaría un inevitable grado de artificiosidad y formalismo en la delimitación de la tutela judicial demandada por la Constitución ${ }^{67}$, ya que conduciría al aplicador jurídico a desentenderse de las argumentación de las resoluciones judiciales y, consecuentemente, de las propias decisiones judiciales. Finalmente, esta perspectiva se arriesga a la crítica de abrir paso una tutela judicial más formal que efectiva.

Por otra parte, el ámbito del derecho a la tutela judicial efectiva reconocido por nuestra Constitución nos ha evitado arduas discusiones, en primer lugar, acerca de cómo superar el limitado ámbito del derecho de acceso a la jurisdicción, previsible en un contexto de alta judicialización de los conflictos sociales, y, en segundo lugar, sobre cómo garantizar a través del recurso de amparo los contenidos derivados del derecho a un proceso equitativo previsto en el artículo 6 del Convenio Europeo de Derechos Humanos, o, por decirlo de otra manera, cómo engarzar la jurisprudencia del Tribunal Europeo de Derechos Humanos en la del Tribunal Constitucional en lo que se refiere a temas procesales ${ }^{68}$.

${ }^{65}$ Las líneas siguientes surgen de una reflexión posterior a la discusión mantenida en el seminario del Instituto de Derecho Parlamentario de la Universidad Complutense el 11 de abril de 2019 en relación con una ponencia sobre el tema objeto del presente trabajo. Agradezco a Javier García Roca su invitación y a quienes asistieron e intervinieron en el debate sus ideas y críticas.

${ }^{66}$ La obra más destacada en este sentido es BORRAJO INIESTA, I., DÍEZ-PICAZO GIMÉNEZ, I. y FERNÁNDEZ FARRERES, G. (1995); ob. cit., págs. 157-163.

${ }^{67}$ Como admiten los propios autores citados en la nota anterior. Ibidem, pág. 163.

${ }^{68}$ En Alemania, ha sido constante la discusión acerca de cómo superar los límites que se derivan del artículo 19.4 de la Ley Fundamental, que recoge solamente un derecho de acceso a la jurisdicción. La doctrina ha pretendido superar dicha limitación mediante una interpretación sistemática, dirigida a ampliar el ámbito del derecho reconocido en el art. 19.4 de la Ley Fundamental en conexión con otros artículos. Por una parte, para construir un derecho derivado de la Constitución a ejercer la acción en las relaciones entre privados se ha acudido al art. 103.1 de dicha norma, que garantiza el derecho de todos a ser oídos en juicio. Por otra parte, el Tribunal Constitucional Federal alemán ha terminado dando 
Aun siendo conscientes de las dificultades que genera la interpretación del contenido del derecho a la tutela judicial y de la abundante litigiosidad que aquél genera ante el Tribunal Constitucional a través del recurso de amparo ${ }^{69}$, entendemos que los efectos positivos que ha tenido el reconocimiento de este derecho en los términos del artículo 24 de la Constitución han compensado con creces dichos inconvenientes. En particular, la exigencia de razonabilidad en el discurso judicial que incorpora supone un elemento de vital importancia para el afianzamiento de nuestro Estado de Derecho $^{70}$. Muestra de ello es que la jurisprudencia del Tribunal Constitucional sobre este derecho ha cambiado la manera de impartir justicia, al descartar ejercicios formalistas, rigoristas o ficticios de la función judicial y poner el empeño en un ejercicio de la función judicial atento a los intereses reales de las partes ${ }^{71}$.

Ciertamente, la interpretación del derecho a la tutela judicial lleva en sí un grado de incertidumbre y de imprecisión, pero, estimamos, esto no es sino confirmación de que nos hallamos ante una materia de índole constitucional. En efecto, ponderar y adaptar la aplicación de los derechos a los intereses en juego es la práctica cotidiana del Derecho constitucional. Sólo cabe recomendar al Tribunal Constitucional un criterio coherente y constante en la aplicación de los tests que sirven de instrumento para resolver los casos en los que resulta afectado este derecho y un esfuerzo de argumentación para explicar suficientemente los casos en los que se aparte de dichos tests o en que aplique tests auxiliares que apuntan a la justicia material o a una interpretación finalista de las normas.

amparo a las garantías del proceso a partir de una interpretación sistemática del artículo 19.4 con el artículo 101, que establece el derecho de toda persona al juez legal, y del artículo 92, que atribuye el poder judicial a los jueces. Un sector de la doctrina ha acudido, incluso, al art. 6 del Convenio Europeo de Derechos Humanos a tal fin. Para el debate doctrinal en Alemania, vid. FIGUERUELO BURRIEZA, A. (1990); ob. cit., págs. 39-40. Incluso, el Tribunal Constitucional Federal alemán, en una sentencia de 15 de diciembre de 2015, ha explorado la opción de vincular el derecho de acceso al proceso a la garantía de la dignidad humana para, a partir de esta, deducir la necesidad de respetar las garantías procesales inherentes a un proceso justo.

${ }^{69}$ Así como de los ocasionales conflictos entre el Tribunal Constitucional y el Tribunal Supremo. A este respecto, LÓPEZ GUERRA, L. (1997). «Jurisdicción ordinaria y jurisdicción constitucional», en RUIZ-RICO RUIZ, G. (Ed.); La aplicación jurisdiccional de la Constitución, Valencia, Tirant lo Blanch, págs. 52-55, en relación con la STC 7/1994; y DELGADO DEL RINCÓN, L. E. (2007). «Los conflictos entre la Sala Primera del Tribunal Supremo y el Tribunal Constitucional», Revista General de Derecho Constitucional, 4, http://www.iustel.com/v2/revistas/detalle_revista.asp?id=3\&numero=4.

${ }^{70}$ FIGUERUELO BURRIEZA, A. (1990); ob. cit., pág. 51.

71 RUIZ-RICO RUIZ, G. y CARAZO LIÉBANA, M. J. (2013); ob. cit., pág. 14, CHAMORRO BERNAL, F. (1994); ob. cit., pág. 4, LÓPEZ GUERRA, L. (1997); ob. cit., pág. 45, y CARRASCO DURÁN, M. (2018); ob. cit., págs. 68-70. 


\section{BIBLIOGRAFÍA}

Acosta Estévez, J. B. (1987). Los derechos básicos del justiciable, Barcelona, PPU.

AjA, E. (1991). «Prólogo», en Ruiz Ruiz, G.; El derecho al juez ordinario en la Constitución española, Madrid, Civitas.

Albácar López, J. L. (1983). «Contenido y alcance del derecho a la tutela jurisdiccional», El Poder Judicial, Madrid, Instituto de Estudios Fiscales.

Almagro Nosete, J. (1983). «Comentario al art. 24 CE», en Alzaga Villamil, O.; Comentarios a las leyes políticas, Madrid, EDERSA.

Alonso García, E. (1991). «El art. 24.1 de la Constitución en la jurisprudencia del Tribunal Constitucional: problemas generales y acceso a los Tribunales», en Estudios sobre la Constitución Española. Homenaje al Profesor Eduardo García de Enterría, t. II, Madrid, Civitas.

Beladiez Rojo, M. (2002). «El derecho a la tutela judicial efectiva y garantías constitucionales del proceso", AA. VV.; Las libertades de información y de expresión: actas de las VII Jornadas de la Asociación de Letrados del Tribunal Constitucional, Madrid, CEPC.

Borrajo Iniesta, I., Díez-Picazo Giménez, I. y Fernández Farreres, G. (1995). El derecho a la tutela judicial y el recurso de amparo. Una reflexión sobre la jurisprudencia constitucional, Madrid, Civitas.

Bujosa Vadell, L. y Rodríguez García, N. (1999). «Algunos apuntes sobre el derecho a la tutela judicial efectiva en la jurisprudencia constitucional», La Ley, 2.

Cabañas García, J. C. (2013). «El derecho fundamental de acceso a la justicia civil y su configuración por el Tribunal Constitucional», Revista General de Derecho Constitucional, 16.

Calaza López, S. (2011). «Principales proyecciones del derecho a la tutela judicial efectiva en la doctrina del Tribunal Constitucional», Revista General de Derecho Procesal, 23.

Carrasco Durán, M. (2018). El derecho a la tutela judicial efectiva sin indefensión, Cizur Menor, Thomson Reuters Aranzadi.

Carrasco Durán, M. (2004). «Novedades sobre la interpretación del derecho a la tutela judicial efectiva», Revista del Poder Judicial, 76.

Chamorro Bernal, F. (2005). El artículo 24 de la Constitución, t. I, El derecho de libre acceso a los Tribunales, Barcelona, Iura Editorial.

Chamorro Bernal, F. (1994). La tutela judicial efectiva, Barcelona, Bosch.

De La Oliva Santos, A. (1980). Sobre el derecho a la tutela jurisdiccional, Barcelona, Bosch.

De La Oliva Santos, A. (1996). «Tribunal Constitucional y jurisdicción ordinaria: causas, ámbitos y alivios de una tensión», en De La Oliva SANTos, A. y Díez-Picazo Giménez, I.; Tribunal Constitucional, Jurisdicción ordinaria y derechos fundamentales, Madrid, McGraw Hill. 
Delgado Del Rincón, L. E. (2007). «Los conflictos entre la Sala Primera del Tribunal Supremo y el Tribunal Constitucional: génesis, evolución y algunas propuestas de solución», Revista General de Derecho Constitucional, 4.

Díez-Picazo, I. (1996). «Artículo 24», en Alzaga Villaamil, O.; Comentarios a la Constitución Española de 1978, vol. 3, Madrid, Edersa.

Dítz-Picazo, L. (1987). «Notas sobre el derecho a la tutela judicial efectiva», Poder Judicial, 5.

Díez-Picazo, L. M. (2013). Sistema de Derechos Fundamentales, Madrid, Thomson Civitas, Madrid, 4. ${ }^{\mathrm{a}}$ ed.

Figueruelo Burrieza, A. (1990). El derecho a la tutela judicial efectiva, Madrid, Tecnos.

Garberí Llobregat, J. (2008). El derecho a la tutela judicial efectiva en la jurisprudencia del Tribunal Constitucional, Barcelona, Bosch.

Gil-Robles Y Gil-Delgado, A. (1996). Los nuevos límites de la tutela judicial efectiva, Madrid, Centro de Estudios Constitucionales.

Gimeno Sendra, V. (1981). Fundamentos del Derecho procesal, Madrid, Civitas.

Gimeno Sendra, V. (2015). Introducción al Derecho Procesal, Madrid, UNED.

Gómez Ferrer-Morant, R. (1985). «La tutela judicial efectiva como derecho fundamental», en MARTÍN-RETORILlo BAQUER, L.; De la jurisprudencia del Tribunal Constitucional: Seminario de profesores de la Facultad de Derecho, Zaragoza, Institución «Fernando el Católico».

GonzÁlez Montes, J. L. (1983). «Notas en torno al derecho a la tutela jurisdiccional en la Constitución Española», El Poder Judicial, Madrid, Instituto de Estudios Fiscales.

González Pérez, J. (1984). El derecho a la tutela jurisdiccional, Madrid, Civitas.

IgARTUA SAlaverría, J. (2003). La motivación de las sentencias, imperativo constitucional, Madrid, CEPC.

López GUERRA, L. (1997). «Jurisdicción ordinaria y jurisdicción constitucional», en RuIz-Rico RuIz, G. (Ed.); La aplicación jurisdiccional de la constitución, Valencia, Tirant lo Blanch.

MARTín Diz, F. (2019). «El derecho fundamental a justicia: revisión integral e integradora del derecho a la tutela judicial efectiva», Revista de Derecho Político, 106.

Mateu-Ros Cerezo, R. (1982). «El derecho constitucional a la tutela judicial efectiva y el requisito de la legitimación», Revista de Administración Pública, 98.

Medina Guerrero, M. (1996). La vinculación negativa del legislador a los derechos fundamentales, Madrid, McGraw Hill.

Milione, C. (2015). El derecho a la tutela judicial efectiva en la jurisprudencia del Tribunal Europea de Derechos Humanos, Valencia, Tirant lo Blanch.

Morenilla Allard, P., Torres Del Moral, A., Gimeno Sendra, V. y Díaz MARTíneZ, M. (2018). Los derechos fundamentales y su protección jurisdiccional, Madrid, Edisofer, 3. ${ }^{\mathrm{a}}$ ed.

(C) UNED. Revista de Derecho Politico 
Moreno Catena, V. y otros (1988). Derecho Procesal, t. I, vol. I, Valencia, Tirant lo Blanch.

Naranjo Román, R. (2019). El recurso de amparo. La especial trascendencia constitucional en la jurisprudencia del Tribunal Constitucional, Valencia, Tirant lo Blanch.

Pérez Royo, J. (2018). Curso de Derecho Constitucional, Madrid, Marcial Pons, 16. ${ }^{a}$ ed.

Pérez-Ugena Coromina, M. (2014). «Garantía del derecho a la tutela judicial efectiva en los sistemas principales de resolución de conflictos: arbitraje y mediación», Estudios de Deusto, vol. 62/1.

Rubio Llorente, F. (1995). «El recurso de amparo constitucional», en AA. VV.; La jurisdicción constitucional en España. La Ley Orgánica del Tribunal Constitucional: 1979-1994, Madrid, CEC.

Ruiz-Rico Ruiz, G. y Carazo LiéBana, M. J. (2013). El derecho a la tutela judicial efectiva. Análisis jurisprudencial, Valencia, Tirant lo Blanch.

SÁnCHEZ BARrios, M. I. (2010). «La acción como derecho a la tutela judicuial efectiva», Justicia. Revista General de Derecho Procesal, 1-2.

TARuffo, M. (1975). La motivazione della sentenza civile, Padua, CEDAM.

Tur Ausina, R. (2008). Garantía de derechos y jurisdicción constitucional. Efectividad del amparo tras la sentencia estimatoria, Valencia, Tirant lo Blanch

Viver Pi-Sunyer, C. y López-Bofill, C. (2006). «Derecho a la tutela judicial efectiva sin indefensión», en VIVER PI-SUnYeR, C. (Coord.); Jurisdicción constitucional y judicial en el recurso de amparo, Valencia, Tirant lo Blanch.

Title:

The Right to the effective protection of Judges and Courts as defined in the Spanish Constitution.

\section{Summary:}

Introduction.- 1. The right to the effective protection of judges and courts: an ungraspable notion beyond Constitutional Law academic circle.- 2. The full scope of the right to the effective protection of judges and courts.- 3 . The judgment on reasonableness: dimensions and tests- 4 . Conclusion and criticism.- Bibliography 


\title{
Resumen:
}

El derecho a la tutela judicial efectiva ha sido escasamente estudiado por la doctrina del Derecho Constitucional. Sin embargo, este derecho está presente en la mayor parte de las demandas que llegan al Tribunal Constitucional a través del recurso de amparo, y por ende en la mayoría de las sentencias que aquél dicta. El contraste entre uno y otro dato se debe a la percepción que existe acerca de la naturaleza predominantemente procesal de este derecho. Esta percepción aboca en muchas ocasiones a una mala comprensión del citado derecho.

La finalidad del presente trabajo es delimitar el derecho a la tutela judicial efectiva desde su naturaleza constitucional, sobre la base de la jurisprudencia del Tribunal Constitucional. Se afirmará que el derecho a la tutela judicial efectiva abarca todo el proceso y que, por tanto, no es posible delimitar este derecho a partir del tradicional esquema basado en la distinción entre un contenido de naturaleza constitucional y un contenido de legalidad «ordinaria». Por el contrario, lo que distingue al derecho a la tutela judicial efectiva es la perspectiva que obliga a adoptar a quien desee fundamentar en él su argumentación. El derecho a la tutela judicial efectiva no permite revisar el acierto de las resoluciones judiciales, sino la razonabilidad de la argumentación desarrollada por los órganos judiciales para fundamentar sus resoluciones.

De esta manera, la argumentación basada en el derecho a la tutela judicial efectiva distingue varias vertientes en este derecho y aplica una serie de tests, que dan la medida de la razonabilidad exigida a las resoluciones judiciales en cada caso. El presente trabajo detalla, precisamente, estas vertientes y tests. Ello da lugar a que la doctrina sobre el derecho a la tutela judicial efectiva sea imprecisa, ya que emplea conceptos tales como la razonabilidad, la proporcionalidad, la eficacia o la finalidad de las actuaciones judiciales y el contexto de los casos, entre otros. Sin embargo, esta característica no puede sorprender, ya que es inherente, precisamente, a su no siempre bien comprendida naturaleza de derecho fundamental.

\begin{abstract}
:
The right to the effective protection of judges and courts has been poorly studied by Spanish Constitutional Law experts. Yet this right is at stake in most individual appeals for protection filed before the Spanish Constitutional Court (recursos de amparo) hence in most Constitutional Court judgements. This contrast is due to a widespread misperception of this right as mostly concerned with Procedural Law matters. The purpose of this article is to approach the right to the effective protection of judges and courts from a strictly constitutional perspective, based on the case law produced by the Spanish Constitutional Court. Its basic assumption is that all judicial acts are covered by the constitutional right to the effective protection of judges and courts, hence that the classic distinction between the constitutional and the ordinary legal content of this right is
\end{abstract}

(C) UNED. Revista de Derecho Politico 
not appropriate. What singles out this right to the effective protection of judges and courts is rather the perspective it forces all legal actors to adopt. Although it does not subject the accuracy of judicial decisions to constitutional review, it allows for the constitutional review of the reasonableness of the arguments that sustain them. It does so through a series of tests that convey the degree of reasonability that is required from judicial rulings in every case. The present study explores these tests as applied to the different dimensions of the right to the protection of judges and courts. The richness of these dimensions and the diversity of the cases where they appear makes case law on the matter necessarily imprecise, as it relies on open-ended concepts such as reasonableness, proportionality or efficiency, among others. Such imprecision is however hardly surprising, indeed it is inherent to the nature of this right as a constitutional right.

\section{Palabras clave:}

Tutela judicial; jueces y tribunales; proceso; derechos fundamentales; argumentación judicial

Key words:

Effective protection of judges and courts; judicial procedures; fundamental rights; legal reasoning 